\title{
Technical and Economic Evaluation of Pinavia Interchange in Comparison with Roundabout Intersection by AIMSUN
}

\author{
Kamran Rahimov ${ }^{a^{*}}$, Alireza Motamadnia ${ }^{\mathrm{b}}$, Sadegh Samadic \\ ${ }^{a}$ Assistant Professor, Tehran Payamnoor University, Tehran, Iran. \\ ${ }^{b}$ PhD Student in Transportation Engineering, Faculty Member of Islamic Azad University. \\ ${ }^{c}$ MSc in Road and Transportation Engineering, Tehran Payamnoor University.
}

Received 12 March 2016; Accepted 8 April 2016

\begin{abstract}
Interchanges that are investigated in this research are roundabout interchange and Pinavia interchange that are simulated in AIMSUN software using traffic data. The parameters that are considered for each interchange are traffic volume, pollutant emissions, fuel consumption, travel time, delay time ,construction cost, repair and maintenance cost, travel time cost, fuel consumption cost and safety, so that in technical evaluation traffic volume, pollutant emissions, fuel consumption, travel time, delay time are compared by using two independent sample $t$ - test that are used for comparing of two group of data and It is assumed that the variances are equal. Then In economic evaluation construction cost, repair and maintenance cost, travel time cost, fuel consumption cost and safety are converted into cost by using axis produce way that based on this supposal that storage in exchange for an hour of travel time, increase an hour of production opportunities and construction cost, repair and maintenance cost calculated by executive plans and Related Regulations and finally each parameter is weighted by AHP and obtain the universal (total) cost. Finally due to the total cost of the resulting it can be seen that for twenty-year period Pinavia interchange in compare with roundabout interchange has $49 \%$ more efficient.
\end{abstract}

Keywords: Pinavia Interchange; Roundabout Intersection; Square; Technical and Economic Evaluation.

\section{Introduction}

With the increase in population and Consequently, Growing travel demand the transportation directors encountered with safe and efficient transport of human and goods due to budget and land acquisition limitations. Especially, in highways and crowded ways (roads) located at urban and suburban areas that there is no way to capacity increasing. Crowded cause increasing travel time, and reduced safety and also unbearable conditions for driver. In 2004, the study performed for intersections of Louisiana in America by Brian velshon in order to find ways to connect better with intersections design and safety. In this research indicated that four main elements of human factors, traffic considerations, physical elements and economic factors as cost, profit, and energy consumption considered to intersections design. Falhorty (1990) performed research about intersections design in London; he found that the required traffic data for intersection design included peak hour transit volume, rotator movements, public transportation plan, history of accidents and parking places. Afandizadeh and his colleges (2008) results that modification of intersection geometry design affected directly on accidents number and indirectly on speed, traffic volume and queue length but in recent years, converting level crossings to interchanges as a promising and undeniable solution considered to intersections effective management due to current substructures that use of this conversion provided potential sources such as safety increasing, travel time improvement, environmental pollutants reduction, saving capital long-time, reduced fuel consumption, and reduced accidents and fatalities [1].

\section{New type Road Interchange - Pinavia}

Pinavia interchange of four roads (Figure 1) is a two-level intersection with high capacity and no intersecting traffic flows. Due to a unique placement (braiding) of roadways the traffic flows pass each other via four small

\footnotetext{
* Corresponding author: k_rahimov@yahoo.com
} 
overpasses (or tunnels). Traffic goes in a circular motion, and no lanes need to be changed while passing the junction. Radius of all curves in the junction can be set equal or larger than the smallest radius of the curves of the intersecting roads, so the driving speed in the junction can be equal to the speed on the intersecting roads. A large (several hectares) continuous plot of land in the center of the junction is easily accessible without crossing other traffic flows (Figure 2).

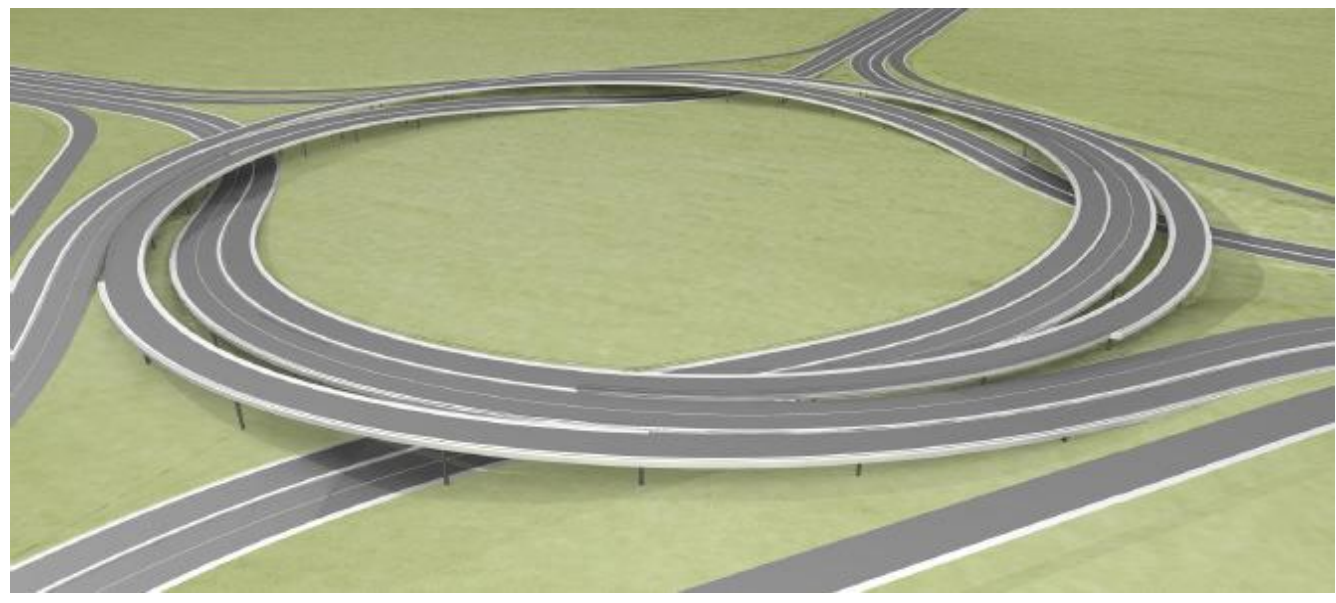

Figure 1. Two-level Pinavia interchange of four roads

Due to an easy access and good strategic position of the territory in the center of the junction it is possible to use it as a large attraction point for passengers by building hotels, sales outlets, centers of logistics etc. [2].

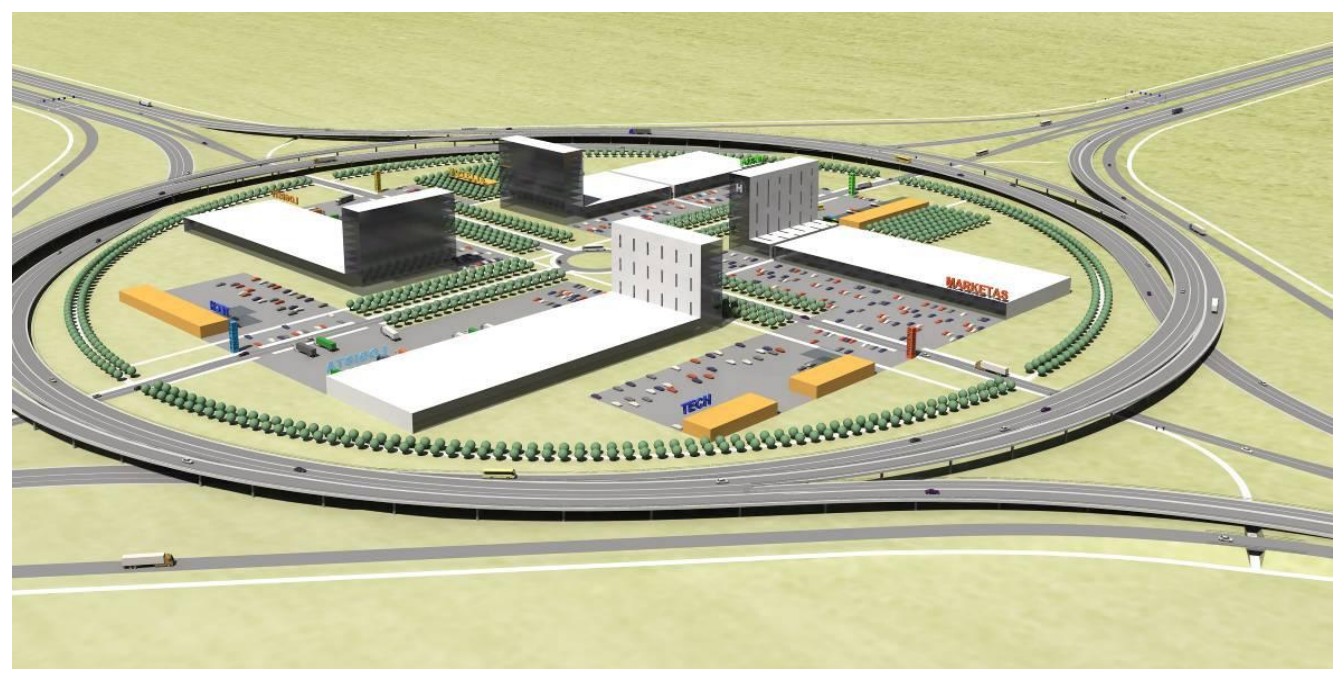

Figure 2. Pinavia interchange (urbanization)

\subsection{Modeling the Pinavia Interchange}

When new interchanges are designed it is imperative to optimize their parameters in order to decrease building costs and area of occupied land. The procedure is quite straightforward in case of the usual interchanges, because parameters of one road do not strongly affect parameters of another. The Pinavia interchange is quite simple from the first look; however, serious complications arise when designing it. Braiding of roadways creates strong dependencies between them and there are several junction variables making essential and non-trivial influence to its final construction parameters (such as its size, length or width of overpasses, size of the land suitable for urbanization etc). In order to use computer optimization a mathematical model of the interchange is needed. Usually straight lines and circular arcs are used to model geometry of roads. A spiral arc is used to smooth the change in centripetal acceleration experienced by a vehicle approaching a circular curve. On railroads during the 19th century, as speeds increased, the need for a track curve with gradually increasing curvature became apparent. Then equations of the so-called clothoid curve, where the curvature is exactly linear in arclength, were derived by several civil engineers independently. The clothoid curve is also known under different names as Euler or Cornu spiral, and most likely was introduced by Leonard Euler in 1744. The clothoid curve (x(t), y(t)) can be parametrized using Fresnel integrals [2],[7]. 


$$
x(t)=\frac{A}{\sqrt{\Pi}} \int_{0}^{t} \cos \frac{\Pi u^{2}}{2} d u, y(t)=\frac{A}{\sqrt{\Pi}} \int_{0}^{t} \sin \frac{\Pi u^{2}}{2} d u
$$

Where A is called a clothoid parameter and length of this curve is $(\mathrm{L})$ :

$$
L=\int_{0}^{t} \sqrt{x^{2}(u)+y^{2}(u)} d u=A \sqrt{\Pi} t
$$

The curvature $\mathrm{k}(\mathrm{t})$ of the clothoid can be computed as a derivative of the angle of rotation $\theta(\mathrm{t})=\pi \mathrm{t}^{2} / 2$ by the length parameter L:

$$
k(t)=\frac{d \theta}{d L}=\frac{d \theta}{d t} \frac{d t}{d L}=\frac{\sqrt{\Pi} t}{A}
$$

Since a curvature radius is $R=1 / k$, we get the formula $A=R L$. The clothoid arc defined on the interval $[0, t]$ blends a horizontal line (x-axis) with an osculating circle at the point $(x(t), y(t))$, see Fig.3. Here the angle $\theta$ and the size of the rectangle can be directly calculated:

$$
\theta=\Pi t^{2} / 2, \omega=\mathrm{x}(\mathrm{t})-\mathrm{R} \sin \theta, \mathrm{h}=\mathrm{y}(\mathrm{t})-\mathrm{R}(\cos \theta-1)
$$

We can apply rotation and/or reflection in order to create a transition curve between a line and a circle in arbitrary position. This construction can be used twice in case when two consequent turns should be performed (Figure 4). To model the driving through the Pinavia interchange it is necessary to make a sequence of several maneuvers: e.g. turn right, then left and finally once more right to drive straight (cf. Figure 1). Any of these paths depend only on the center position and radius of the big circular arc. Given the radius (it corresponds to the designed driving speed) and considering a symmetric case where all other directions are obtained by 90 degree rotations, this becomes a two parameter optimization problem. In practice, minimization of a cost function (a sum of land, road and overpass prices) is performed. The area of land is estimated by a ring bounded by the minimal and the maximal circles; the road price is calculated using the total length of roads, and the overpass prices are derived from their approximated area. Also, several other constraints should be applied: roads may not collide on the same level, and sufficient distance between the overpasses should be maintained (depending on the allowed slope of roads).

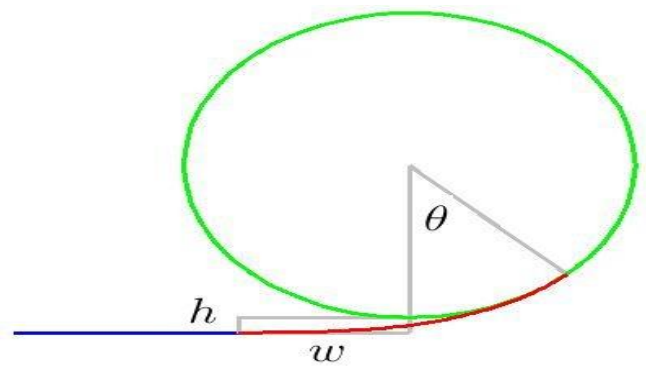

Figure 3. Clothoid curve [3]

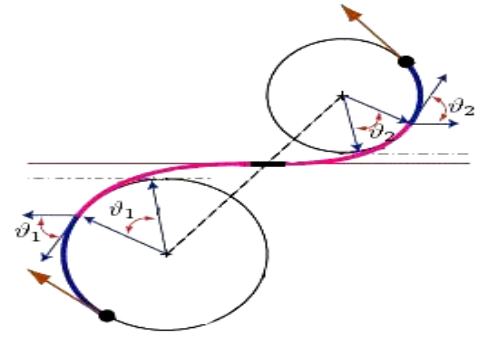

Figure 4. Clothoids of two consequent turns [3]

\section{Define the Problem and Research Purposes}

One of the solutions to improving the situation of the intersections that is considered by Engineers is geometric design modification, traffic restrictions, and schedule with traffic light that is one of the low cost solutions. If these solutions can not solve intersection traffic problems to convert level crossing to interchange is considered. Due to much variety in interchanges and their operational area and also their different economic cost, there are different options to select interchanges kind. Existing model can represent economic and technical factors as a total frame to optimize selection of interchange kind one of the main requirements of engineers. Thus, it is necessary to create uniformity,codify uniform ways and designing,executive and managing criteria of this model due to can use as a expert judgement and guide.Suitable action of interchanges in increasing safety and capacity of roads cause extensively applying them in urban and suburban networks. Regarding to variety of shape and pattern of these intersections, optimize selecting of intersection kind that is satisfied the environmental and traffic conditions and also include economic considerations is important. Due to extensive affecting factors in intersections design and management can not be represented any final and necessary instruction for it. However, it is necessary to create much 
uniformity, is codified series of design and management methods and criteria and along with expert judgment be used as a guide.the purpose of this research is recognition affecting factors in performance of each of the intersections kind such as traffic volume, air pollutant rate, fuel consumption rate, travel time, delay time, cost of accidents, production cost, maintenance and safety cost and representing a instruction to help engineers in order to optimize selection of interchange kind in a special place [3], [8].

\section{Methodology of Research}

The parameters that are investigated in this study and enter in equations as follows traffic volume,air pollutant rate, fuel consumption rate,travel time,cost of construction, maintenance and accidents cost. in the first step ,after preparing traffic information from Tabriz traffic organization and selecting simulator software (AIMSUN), Pinavia interchange and roundabout intersection (Azerbaijan square, Tabriz, Iran) are modelled according to certain case. In the following , Modelled intersections were setting under traffic volume of 10000 vehicle/h and 6 different scenarios included: 1) Turn left and right equally, assuming $10 \%$ heavy vehicles; 2) Heavy turn left and light turn right assuming $10 \%$ heavy vehicles; 3) light turn left and heavy turn right assuming 10\% heavy vehicles; 4) Turn left and right equally, assuming $20 \%$ heavy vehicles; 5) Heavy turn left and light turn right, assuming 20\% heavy vehicles; 6) light turn left and heavy turn right,assuming $20 \%$ heavy vehicles and the software totally was run 90 times for each model and the after software calibration according to square data that had been prepared, outputs of software extracted. In the following and using outputs of AIMSUN software for mentioned parameters an equation based on traffic volume rate,air pollutant rate,fuel consumption rate,travel time,delay time,cost of construction, and accidents reduction cost that are playing determinant role to select optimized plan as interchanges and/or intersections in the last step, all of the parameters turn to Rial price by using of Production-oriented method and finally, the interchange and intersection total cost is obtained by entering physical weight of each parameter that by using AHP and expert experience. As a result, the intersection with low cost and high technical advantages is introduced as a selected intersection [4].

\section{Simulation Intersections in AIMSUN Software}

Two types of intersections were simulated due to regulations in this study. Figure 1 is shown simulation roundabout intersection and figure 2 is shown simulation Pinavia interchange.

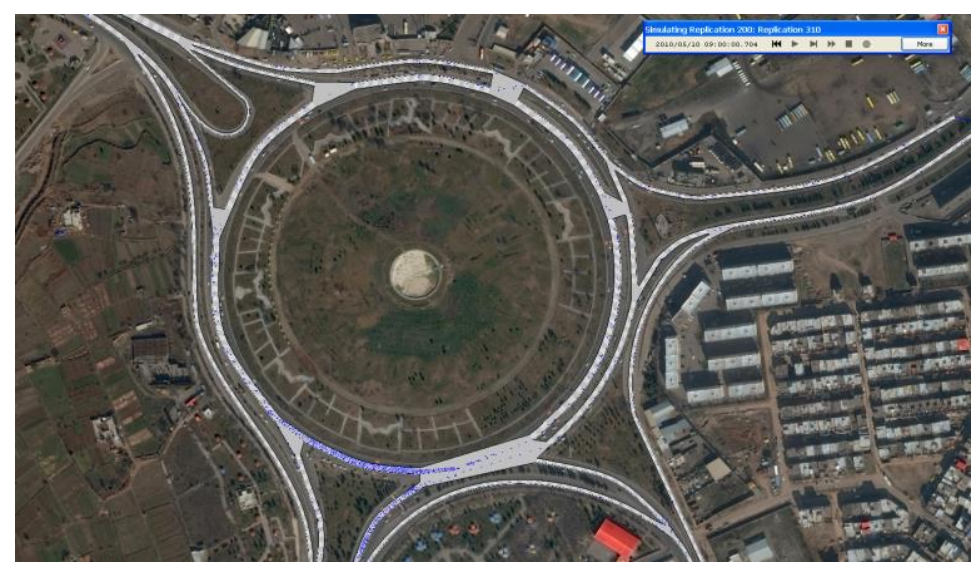

Figure 5. Simulation roundabout intersection in AIMSUN

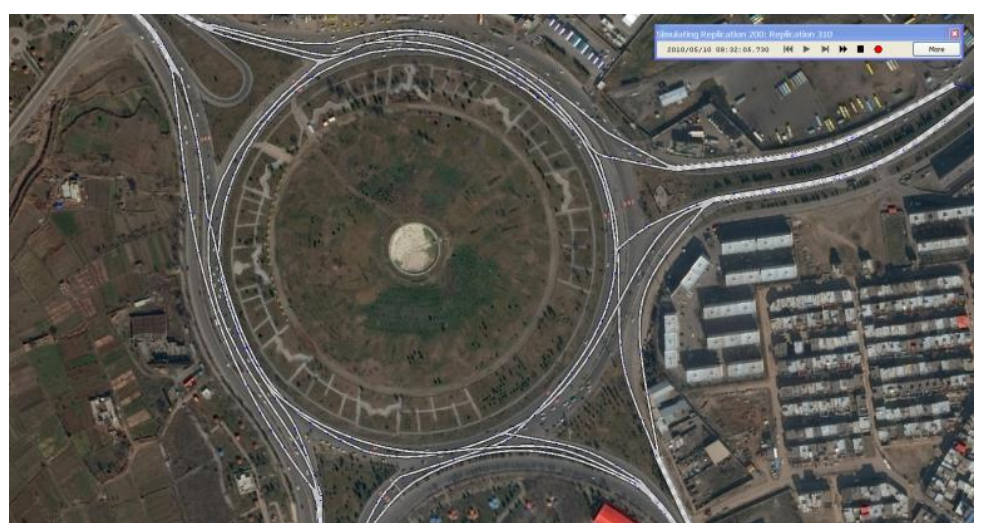

Figure 6. Simulation Pinavia interchange in AIMSUN

Due to there is no possible to direct study about pinavia interchanges in Iran, In this research to compare the 
performance between Pinavia and roundabout using simulation method in small-scale (microscopic simulation) by AIMSUN software.Different traffic scenarios considered in software to obtain the performance of each intersection in terms of capacity,delay time,travel time and also,feasibility of Pinavia interchange and roundabout due to technical and economic conditions is investigated [5].

\section{Evaluation Method and Compare Parameters with Each Other}

To perform a comprehensive comparison between two types of intersections under similar condition, it is necessary to investigate different types of traffic volume.For this reason,inteneded intersection is simulated with traffic volumn of 10000 vehicles/h under 6 different scenarios included: 1) Turn left and right equally,assuming $10 \%$ heavy vehicles; 2) Heavy turn left and light turn right assuming $10 \%$ heavy vehicles;3) light turn left and heavy turn right assuming $10 \%$ heavy vehicles; 4) Turn left and right equally, assuming 20\% heavy vehicles; 5) Heavy turn left and light turn right, assuming $20 \%$ heavy vehicles; 6) light turn left and heavy turn right,assuming $20 \%$ heavy vehicles and the software totally was run 90 times for each model. Finally, After obtaining the software outputs and calculate the average of mean value of six considered scenarios for each parameters and also using AHP method and transportation and traffic experts experiment and opinion, these values compared to 2 intended intersections and finally due to the value of each parameter each of them were prioritized and scored and better plan was selected based on these scores and considered scenarios [6].

\section{Software Outputs}

The results of simulation based on defined scenarios for two considered intersections are shown in table1. The simulation results have different values based on vehicle type (car, truck, etc.), the values of them are shown In table1.

Table1. AIMSUN outputs parameters for 2 intended intersections

\begin{tabular}{|c|c|c|c|c|c|c|c|c|c|c|c|c|}
\hline \multirow[b]{2}{*}{ Parameters } & \multicolumn{2}{|c|}{ Scen.1 } & \multicolumn{2}{|c|}{ Scen.2 } & \multicolumn{2}{|c|}{ Scen.3 } & \multicolumn{2}{|c|}{ Scen.4 } & \multicolumn{2}{|c|}{ Scen.5 } & \multicolumn{2}{|c|}{ Scen.6 } \\
\hline & $\begin{array}{c}\text { Pinavia } \\
\text { Intersection }\end{array}$ & $\begin{array}{l}\text { Roundabout } \\
\text { Intersection }\end{array}$ & $\begin{array}{c}\text { Pinaria } \\
\text { Intersection }\end{array}$ & $\begin{array}{l}\text { Roundabout } \\
\text { Intersection }\end{array}$ & $\begin{array}{c}\text { Pinavia } \\
\text { Intersection }\end{array}$ & $\begin{array}{l}\text { Roundabout } \\
\text { Intersection }\end{array}$ & $\begin{array}{c}\text { Pinavia } \\
\text { Intersection }\end{array}$ & $\begin{array}{l}\text { Roundabout } \\
\text { Intersection }\end{array}$ & $\begin{array}{c}\text { Pinaria } \\
\text { Intersection }\end{array}$ & $\begin{array}{l}\text { Roundabout } \\
\text { Intersection }\end{array}$ & $\begin{array}{c}\text { Pinaria } \\
\text { Intersection }\end{array}$ & $\begin{array}{l}\text { Roundabout } \\
\text { Intersection }\end{array}$ \\
\hline Density & 8.42 & 10.78 & 9.25 & 19.36 & 7.84 & 9.86 & 8.68 & 19.52 & 9.33 & 24.02 & 7.94 & 13.04 \\
\hline Flow & 9486 & 7251 & 9585 & 5922 & 9559 & 7497 & 9599 & 6310 & 9533 & 5077 & 9551 & 7016 \\
\hline Speed & 72.32 & 54.84 & 70.86 & 38.75 & 73.36 & 60.65 & 71.07 & 45.64 & 69.64 & 37.88 & 73.18 & 54.66 \\
\hline Travel Time & 50.08 & 82.86 & 51.07 & 140.35 & 49.44 & 71.06 & 50.97 & 129.77 & 51.98 & 156.41 & 50.2 & 90.59 \\
\hline Total Travel Time & 408.4 & 521.15 & 448.9 & 758.8 & 381.1 & 434.7 & 421.4 & 748.8 & 452.7 & 748.1 & 386.4 & 523.6 \\
\hline Travel Distance & 29173 & 22098 & 31490 & 19300 & 27563 & 21082 & 29577 & 18934 & 31245 & 16393 & 27530 & 19647 \\
\hline Delay Time & 2.93 & 34.36 & 2.56 & 91.27 & 1.94 & 23.25 & 2.37 & 80.9 & 2.92 & 106.98 & 2.14 & 42.22 \\
\hline Fuel Consumption Rate & 2362.8 & 2246.9 & 2544.7 & 2352.3 & 2236.6 & 2109.2 & 2395.9 & 2734 & 2522.1 & 2267 & 2262.1 & 2289.6 \\
\hline Co pollutant Rate & 24504 & 30729 & 26934 & 45528 & 22866 & 26082 & 25284 & 44928 & 27162 & 44886 & 23184 & 31416 \\
\hline
\end{tabular}

Also, these outputs described by below graphs 1-9.

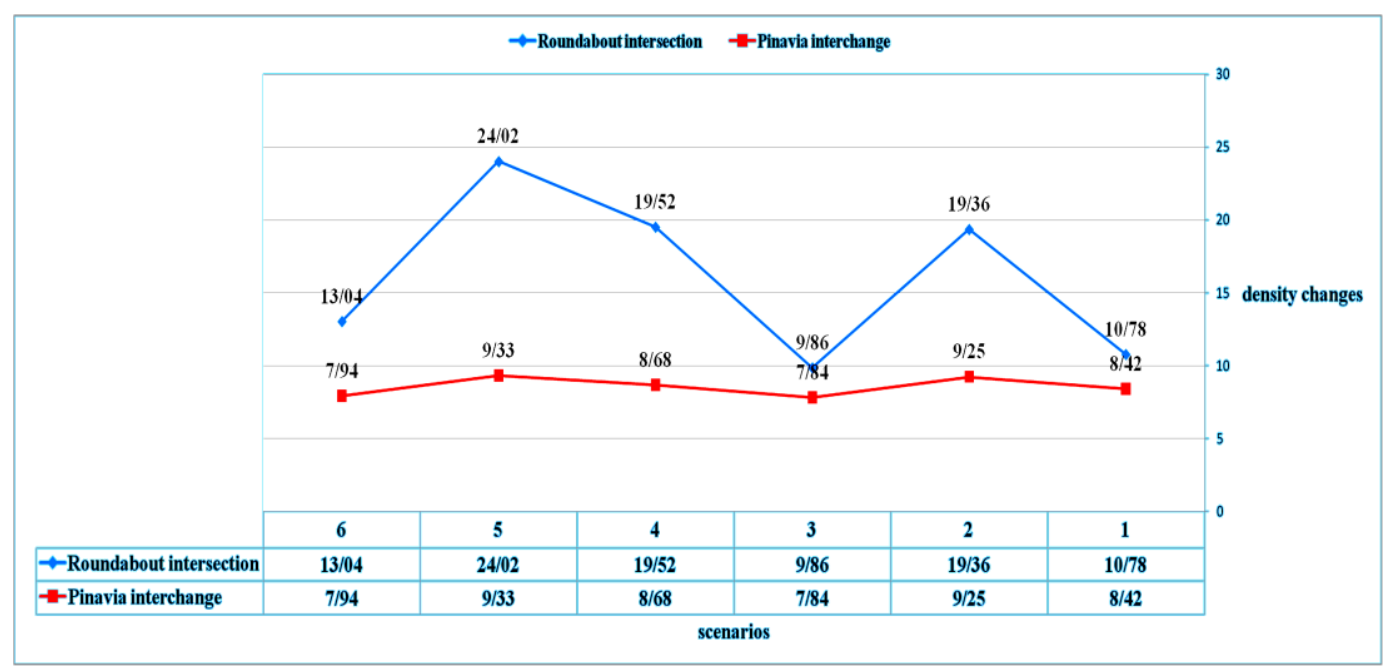

Figure 1. Density changes 


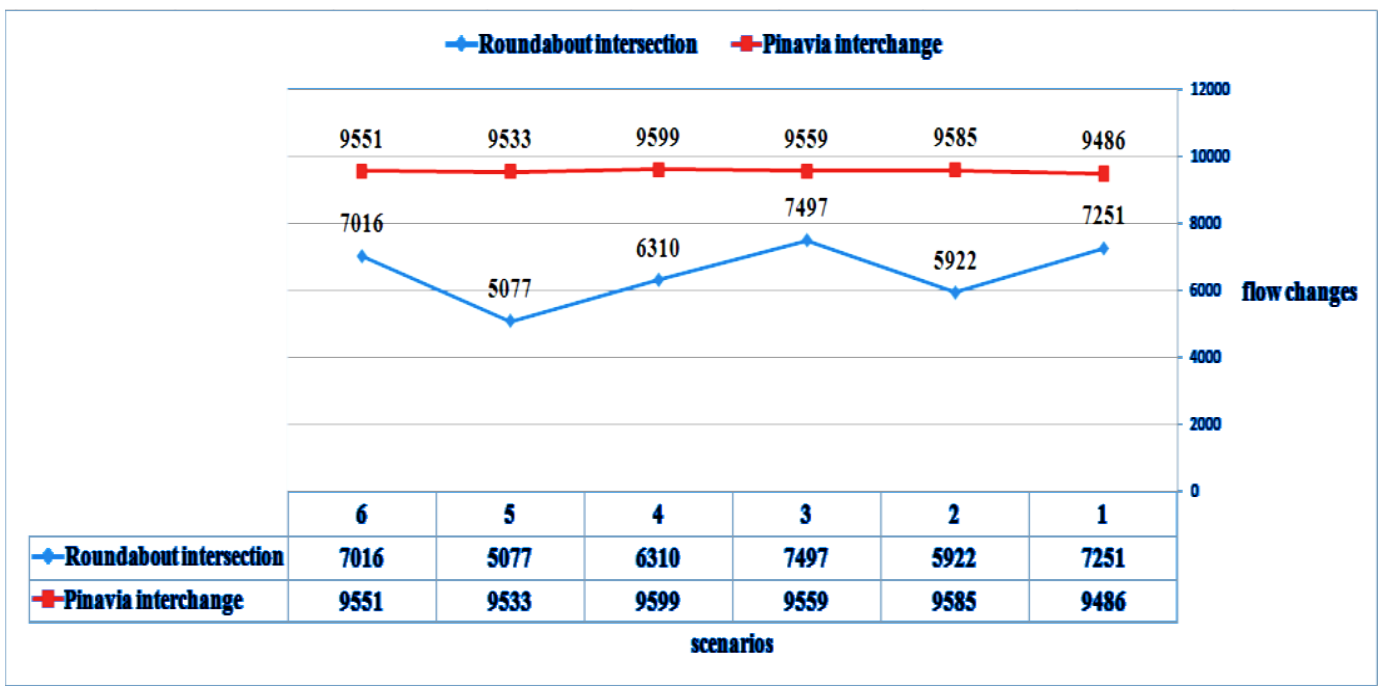

Figure 2. Flow changes

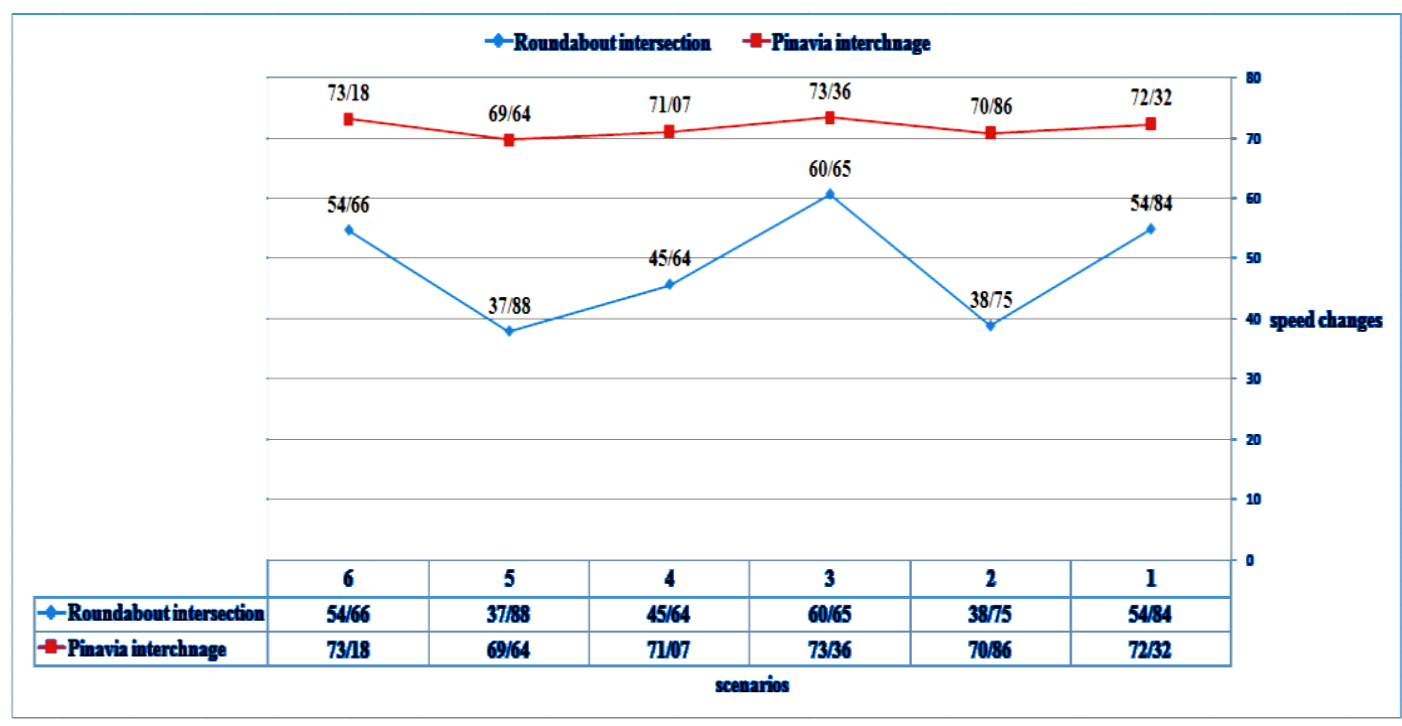

Figure 3. Speed changes

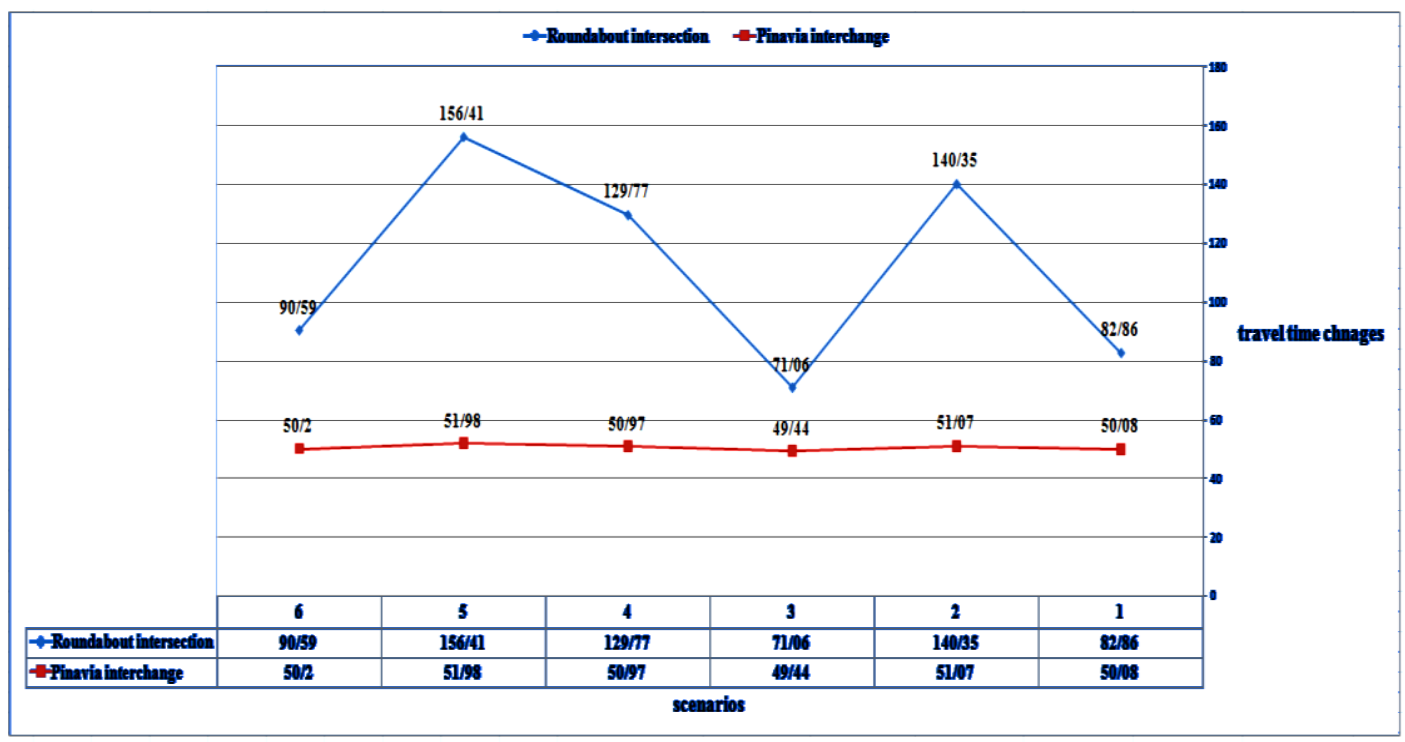

Figure 4. Travel time changes 


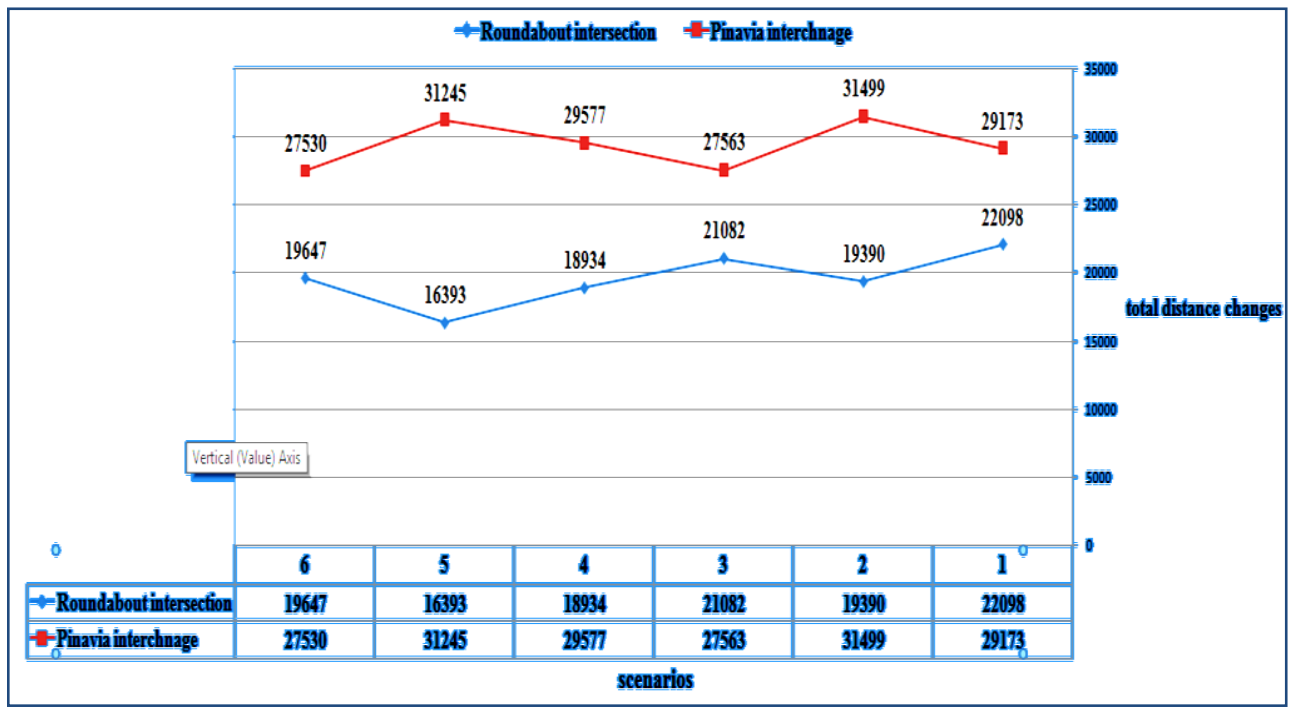

Figure 5. Total travel time changes

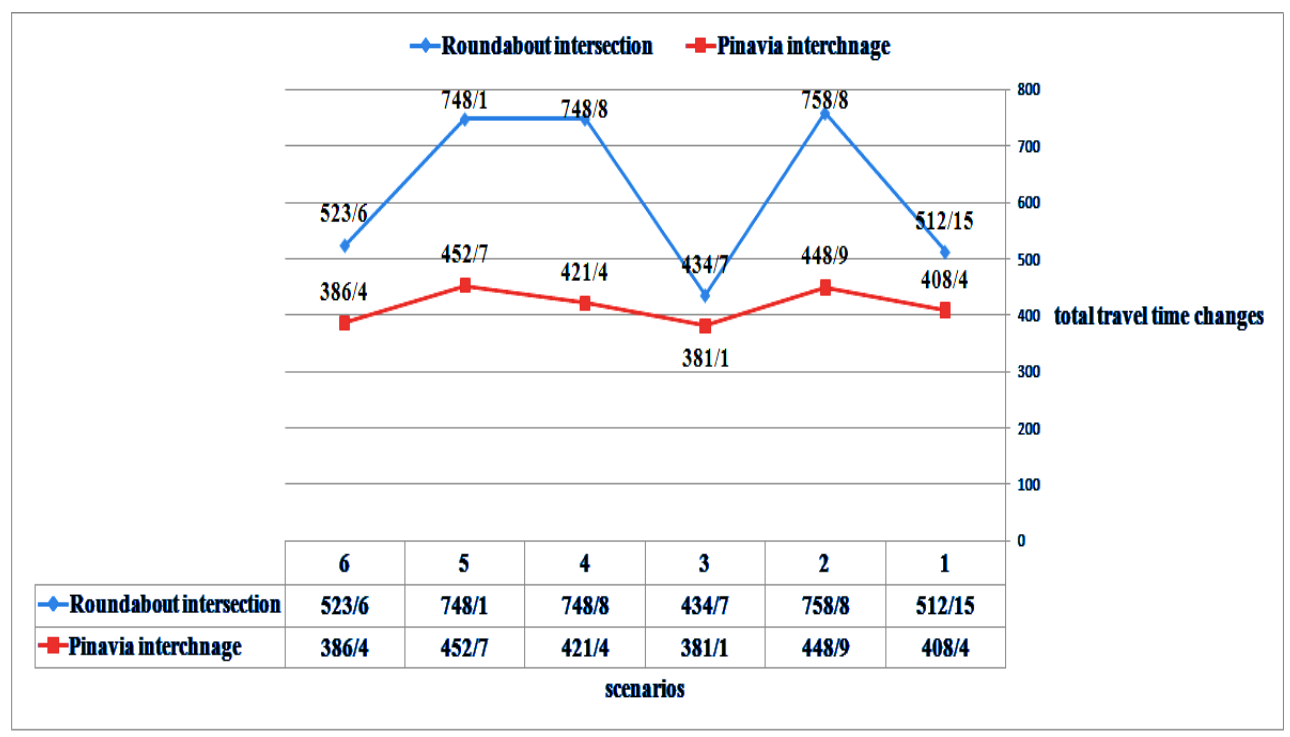

Figure 6. Total distance changes

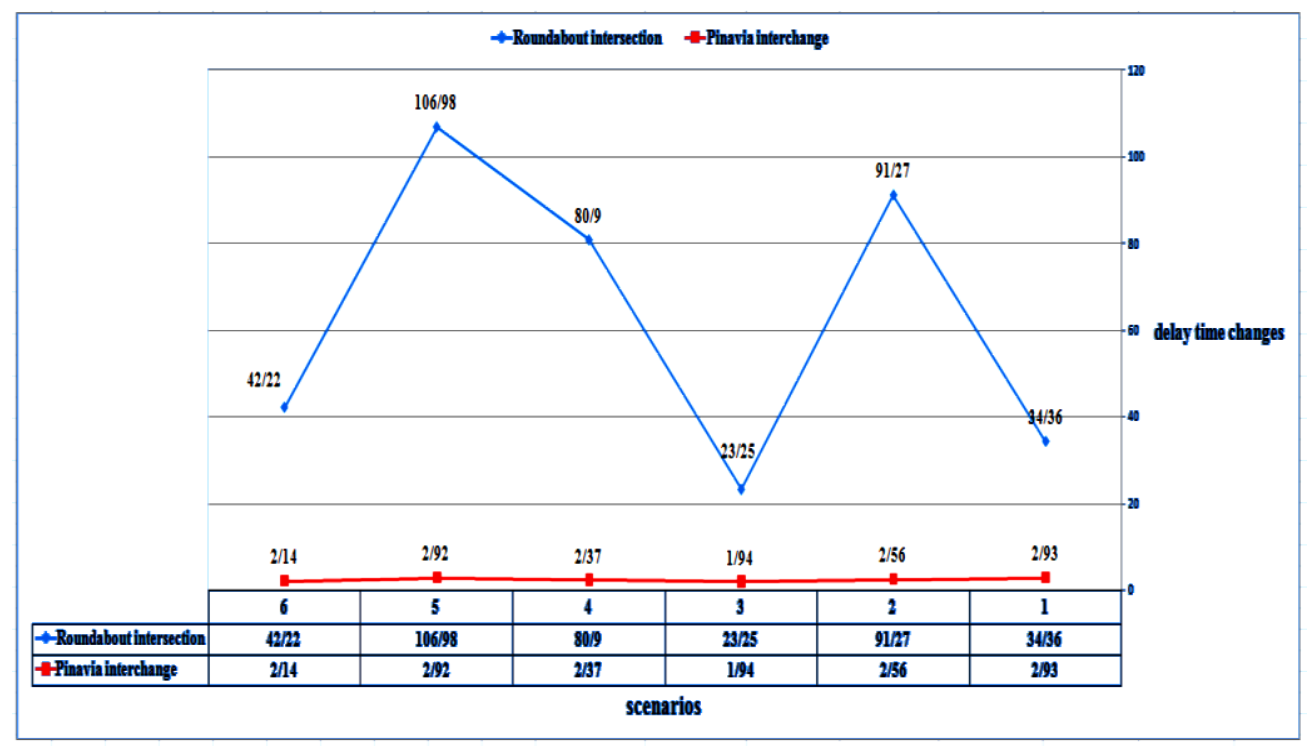

Figure 7. Delay time changes 


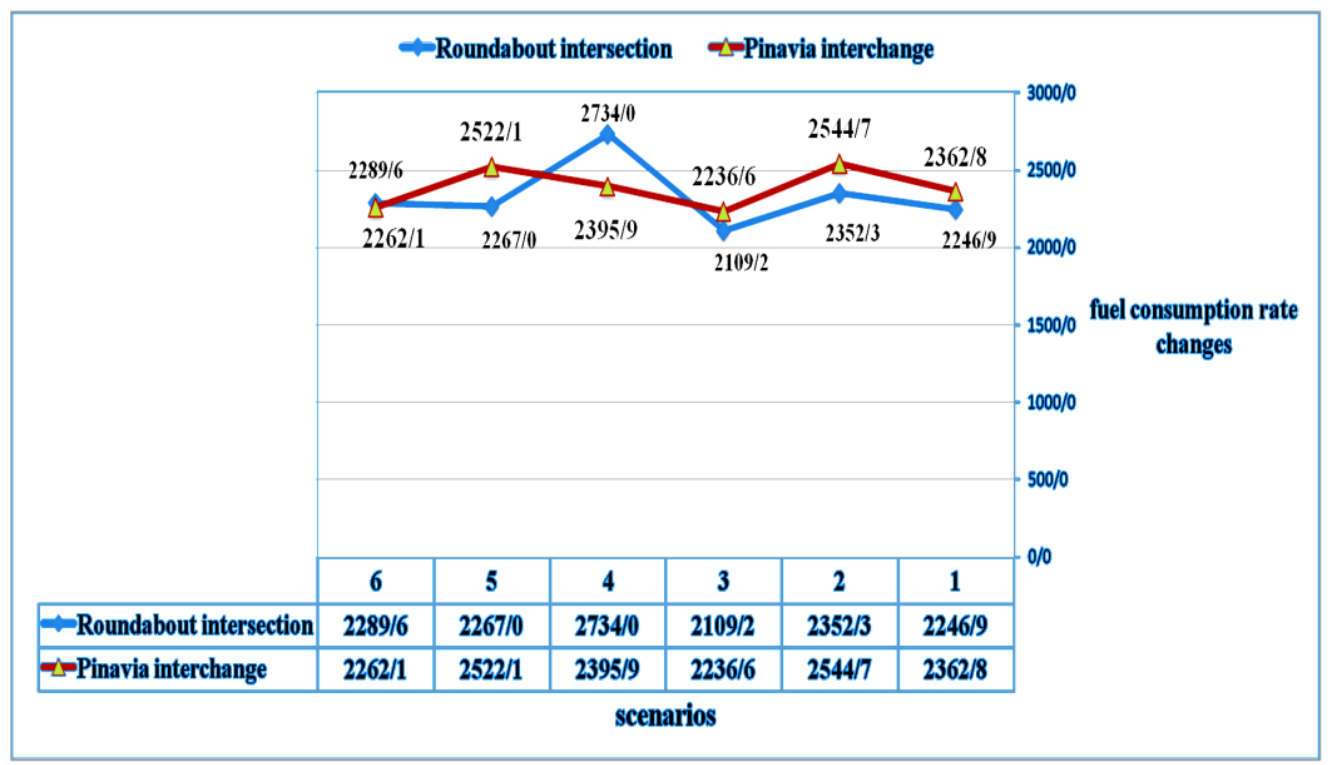

Figure 8. Fuel consumption rate changes

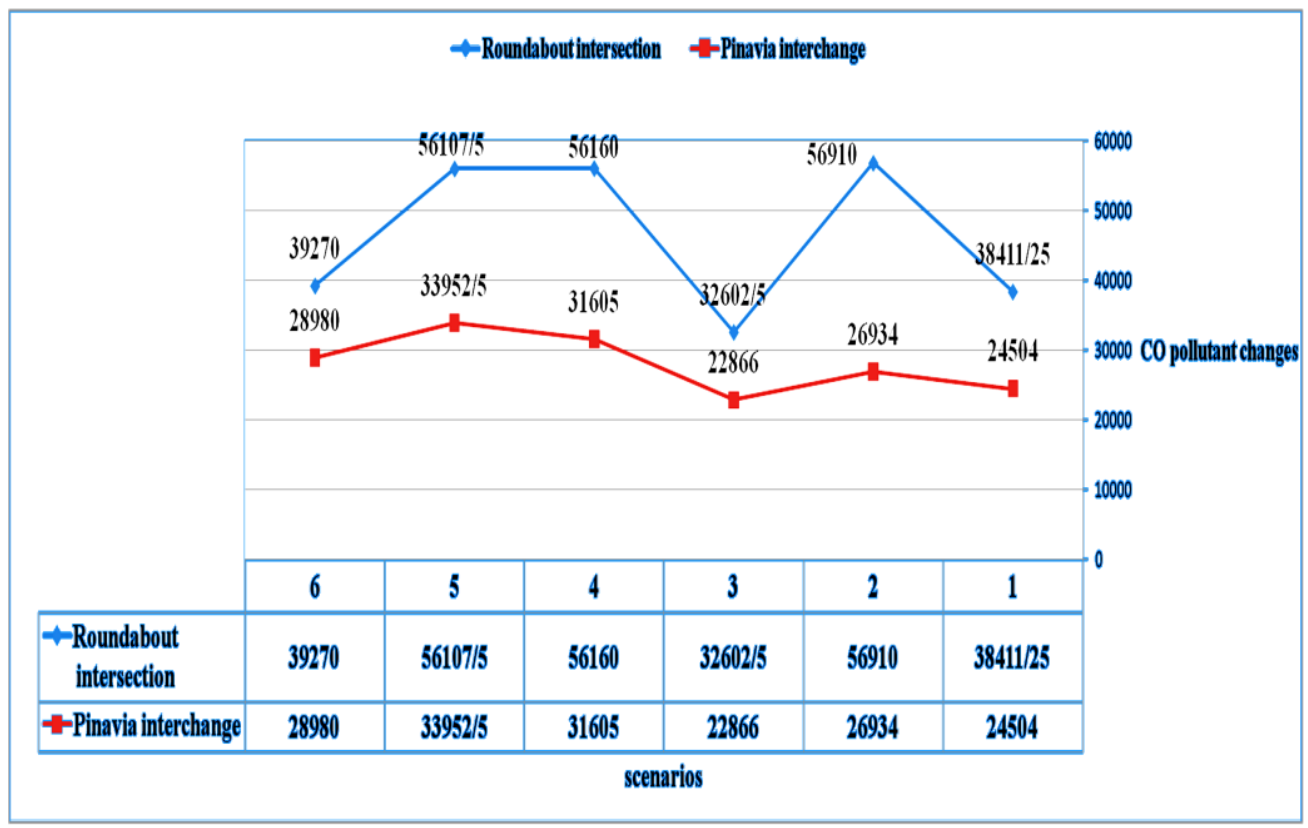

Figure 9. Co pollutant rate changes

With observe table 1 and figures 1-9 resulting that by converting roundabout to Pinavia interchange, the flow density decreases for all defined scenarios. Speed and flow rate increased by intersections replacement. Based on increasing flow rate and speed and density decreased observed that travel and total travel time decreased by replacement of proposed intersection. This replacement caused the number of conflict points decreased 8 to 0 and also delay time decrease for all Scenarios, but according to this point that proposed intersection be interchange and diameter of each direction is high rather than current directions in square, total distance in proposed interchange increased rather than roundabout but seen that for scenarios 1,4 that number of left-turning and right-turning be equal, fuel consumption rate in proposed intersection is less than current intersection but this value for scenarios 2-6 for proposed intersection is more than value of current intersection, and in about of Co pollutant rate value, according to this point that value of this parameter depend on time observed that Co pollutant rate value decrease By total travel time decreasing [6].

\section{Parameters cost estimation}

In the following represent costs of manufacturing, maintenance and accidents and also discuss how the pollution 
parameters, fuel consumption, and travel time cost convert to Rial.

\subsection{Annual Estimation of Manufacturing and Maintenance Cost}

Manufacturing cost included all costs were considered in executive operation of interchange and intersection such as materials and tools, labour, machinery, etc. The advantage of this parameter is its value as Rial. According to this point that manufacturing cost be one of the effective parameters, must be calibrated in a way that is closer to reality, therefore the cost of manufacturing and maintenance of each intersections was extracted and finalized by using collected information of traffic consulting engineers companies and also cost estimation of all the items related to them that respectively obtained as below:

Construction cost of roundabout $=68,316,187,147$

Construction cost of Pinavia interchange $=296,985,048,090$

Maintenance cost of roundabout $=22,470,247,943$

Maintenance cost of Pinavia interchange $=11,966,501,231$

\subsection{Estimation of Fuel Consumption Cost}

Considering 10000 Rials for purchase price, 3500 Rials for gasoline subsidy and generally 13500 Rials as a Final price each gasoline liter and also 0.08 Lit. gasoline for each travel hour resulting that the mean of fuel consumption rate in roundabout intersection and Pinavia is respectively 2333.2 and $2387.4 \mathrm{lit} / \mathrm{h}$, the related cost of them is 31497767.46 and 32229668.88 Rials/h that multiplying these values in $24 * 365$ obtain the mean of annual fuel consumption cost for each of the intersections, these values are as below:

Annual fuel consumption cost of roundabout intersection $=275,920,442,900$ Rials

Annual fuel consumption cost of Pinavia interchange $=282,331,899,400$ Rials

\subsection{Estimation of Co pollutant Cost}

In this research the losses cost due to Co pollutant that cause by traffic networks is considered that is $188 \$ /$ ton and the dollar price is considered 29,000 Rials.There are about 1 million autos in Tabriz and according to Mentioned information and producing 75 tons/h Co pollutant in Tabriz, cost of each ton is calculated by $2900 \times 188=5,452,000$ Rials. According to this point that the mean of total travel time for roundabout and Pinavia Is respectively 621,03 and $416,48 \mathrm{~h}$ resulted that mean of Co pollutant in roundabout and Pinavia is $621.03 \times 75=46577$ ton $/ \mathrm{h}$ and $416.48 \times 75=28140 \mathrm{ton} / \mathrm{h}$ and the relevant cost of them is respectively $46576 \times 5,452,000=253,937,122,500$ and $28140 \times 5,452,000=153,420,643,000 \mathrm{Rial} / \mathrm{h}$ multiplying this value to $24 * 365$ the mean of annual pollutant rate for roundabout and Pinavia is respectively as below [4]:

$$
\begin{aligned}
& 253,937,122,500 \times 24 * 365=2,169,638,775,000,000 \text { Rial } \\
& 153,420,643,000 \times 24 * 365=1,343,964,833,000,000 \text { Rial }
\end{aligned}
$$

\subsection{Estimation of Travel Time Cost in Roundabout and Pinavia}

To estimate travel time cost using production-oriented method (assuming that saving one hour of travel time,one hour production opportunity and also goods production value will be increased). Preliminary calculations of central bank in 2014 indicated that the internal gross production is 151thousand and 886 milliard and 100 million Toman, by dividing this value to $365 * 24$ can be obtained the production rate per hour and multiplying to total travel time of roundabout intersection can obtain travel time value for each of the scenarios and finally mean of travel time value in roundabout and Pinavia.To consider mean of total travel time for roundabout and Pinavia respectively 621.03 and $416.48 \mathrm{~h}$ and internal gross production rate $17338595890.41 \mathrm{Rial} / \mathrm{h}$ resulted that mean of travel time value at roundabout and Pinavia is respectively 10,767,788,210,000 Rials/h and 7,221,178,416,000 Rial/h, by multiplying these values to $24 * 365$, it can be obtained the mean of annual travel time value for roundabout and Pinavia as below [1]:

$10,767,788,210,000 \times 24 * 365=94,325,824,720,000,000$ Rials

$7,221,178,416,000 \times 24 * 365=63,257,522,930,000,000$ Rials 


\subsection{Estimation of Accidents Cost at Roundabout and Pinavia Interchange}

In latest statistic by relevant organizations in 2014, the accidents cost is considered $8 \%$ national gross production. according to this point that the national gross production rate be 151thousand and 886 milliard and 100 million Toman, it can be resulted that paid accidents cost was $12,150,888,000,000$ Rial in 2013, this amount was paid to 530000 accident announced by central insurance institute. The accidents number announced by accident and events commitee is 16800 in Tabriz, this number included $3.16 \%$ of total accidents number of country that by multiplying this percent to $12,150,888,000,000$ Rial can indicate that paid cost to accidents is $3.16 \% \times 12,150,888,000,000=$ $383,968,060,800$ Rial in Tabriz and according to this point that at least 510 accidents occurred in Azarbayjan square (Tabriz) in 2013 and this number presented 3.03\% of total accidents of Tabriz, by multiplying this percent to $383,968,060,800$ Rial that is related to paid costs for all accidents of Tabriz, the paid cost of Azarbayjan square accidents obtain as roundabout shape, this value for each year is as below [1]:

$3.03 \% \times 383,968,060,800=11,634,232,240$ Rial

According to convert roundabout to Pinavia, number of conflict points decrease from 8 to zero, can be said the cost of accidents is zero in this intersection.

\section{Parameters Weighting}

Here, the parameters weight provided by using questionnaire and experts of transportation and traffic and also the professors. According to this point that physical weight of parameters can be function of income, cost, volume, experience and other different factors, in this research, we used AHP method to obtain weight of each parameter. Based on this method, physical weight of construction cost,maintenance cost,fuel consumption cost and cost of Co pollutant, travel time and accidents were determined respectively $0.17,0.10,0.14,0.10,0.7,0.42$.

\section{Total cost of Intersections}

After obtaining parameters weight in previous process, total cost equation is written, for this reason, twenty-year monetary figure of each parameters of manufacturing cost, cost of fuel consumption, Co pollutant, travel time and accidents multiplying to physical weights. Finally, it can be plus the converted parameters with each other and these values are shown in table 9. Thus, the intersections with final low cost will select as a selective intersection.

Table 2. The values of defined parameters in evaluation section of intersections for 20-year utilization life

\begin{tabular}{ccccccc}
\hline W.F & $\mathbf{0 . 1 7}$ & $\mathbf{0 . 1}$ & $\mathbf{0 . 1 4}$ & $\mathbf{0 . 1}$ & $\mathbf{0 . 4 2}$ \\
\hline Intersection & Construction Cost & Maintenance Cost & Fuel Consumption Cost & Co pollutant Cost & Travel Time Cost & Accident Cost \\
\hline Pinavia Intersection & $2.96985 \mathrm{E}+11$ & $2.3933 \mathrm{E}+11$ & $5.64664 \mathrm{E}+12$ & $2.68793 \mathrm{E}+16$ & $1.26515 \mathrm{E}+18$ \\
\hline Roundabout Intersection & $6.83 \mathrm{E}+10$ & $4.49405 \mathrm{E}+11$ & $5.51841 \mathrm{E}+12$ & $4.33928 \mathrm{E}+16$ & $1.88652 \mathrm{E}+18$ & $2.32685 \mathrm{E}+11$ \\
\hline
\end{tabular}

The total cost of roundabout with physical weights for a 20 -year period $=136,396,359,017,039,000$ Rials

The total cost of Pinavia interchange with physical weights for a 20 -year period $=91,249,326,717,779,000$ Rials

\section{Conclusion}

- To convert roundabout to Pinavia, the density at least decrease to 2.02 vehicle/k in scenario 3 and maximum to 14.69 vehicle/k in scen.5, flow rate at least increase to 2062 vehicle/h in scen. 3 and maximum 4456 vehicle/h in scen.5, speed at least increase to $12.71 \mathrm{k} / \mathrm{h}$ for scen. 3 and maximum $32.11 \mathrm{k} / \mathrm{h}$ in scen.2 and travel time significantly decrease for vehicles, so that this reduction is at leaest $21.62 \mathrm{~s} / \mathrm{k}$ in scen. 3 and maximum $104.06 \mathrm{~s} / \mathrm{k}$ in scen.5. By decreasing travel time for each vehicle, total travel time decrease too, so that this reduction is $53.6 \mathrm{~h}$ in scen. 3 and $327.4 \mathrm{~h}$ in scen.4. increasing total distance in Pinavia at least $6481 \mathrm{k}$ in scen 3 and maximum $14852 \mathrm{k}$ in scen.5 is one of disadvantages of this replacement.delay time decrease at least $21.31 \mathrm{~s} / \mathrm{k}$ in scen.3 and maximum $101.06 \mathrm{~s} / \mathrm{k}$ in scen.5 and fuel consumption increase maximum $225 \mathrm{lit} / \mathrm{h}$ in scen.5 and decrease maximum $338.1 \mathrm{lit} / \mathrm{h}$ in scen.4, Co pollutant rate significantly decrease so that maximum decrease of this 19644 ton $/ \mathrm{h}$ in scen. 4 and at least 3216 ton $/ \mathrm{h}$ in scenario 3.

- As considering economic comparison of intersections, the roundabout has significantly economic advantage. Also maintenance cost of intersections in comparison with each other, the Pinavia have economic advantage, about fuel consumption cost, roundabout have relative economic advantage, and in Co pollutant cost and travel time cost the Pinavia have significantly economic advantage. Finally, Pinavia interchange is preferred to roundabout for 20year period according to obtained total cost. 


\section{References}

[1] Raoofi Mahmood , Shariaatmohaymeni Afshin, "Provide a method for sensitivity analysis of traffic simulators parameters" Rahvar scientific - advocacy journal, June 2012, 2th year, no 5.

[2] Aušrius Juozapavičius, Stanislovas Buteliauskas, Rimvydas Krausauskas, "Evaluation of Park\&Ride Facility inside the PINAVIA Junction from the Perspective of Sustainable Development" .The International Journal Of Engineering And Science (IJES), 2010: pp. 51-57.

[3] Aušrius Juozapavičius, Stanislovas Buteliauskas, Rimvydas Krausauskas, "Improvement Possibilities of City Transportation System by Using PINAVIA Interchange”. General Jonas Žemaitis Military Academy of Lithuania, Šilo 5A, 10322 Vilnius. Vilnius University, Department of Mathematics and Informatics, 2010.

[4] Hajihoseinloo Mansoor , Amiramjadi Amir. "The choice of optimal Interchange in Urban networks" The 11th international conference on transportation and traffic engineering, Tehran, Iran, (2012).

[5] Motamadnia , Alireza. “Geometric Design of new roundabouts” M.Sc. seminar, Tehran, Iran, ( 2003 ).

[6] Kazemi mojtaba , hoseinnezhad aziz , heidarpoor bagher and panjaalizadeh bahman "Analysis performance , capacity and safety on roundabouts " Rahvar scientific - advocacy journal , February 2012, 10th year, no 24.

[7] Juozapavičius, Aušrius, Stanislovas Buteliauskas, and Rimvydas Krasauskas. "Improvement Possibilities of City Transportation System by Using PINAVIA Interchange." Environmental Research, Engineering and Management 53, no. 3 (2010): 36-42.

[8] Aušrius Juozapavičius, Stanislovas Buteliauskas, Rimvydas Krausauskas, "Interchange of a New Generation Pinavia” .General Jonas Žemaitis Military Academy of Lithuania, Šilo 5A, 10322 Vilnius.Vilnius University, Department of Mathematics and Informatics, 2010. 